\title{
Treatment modalities for Korean patients with unilateral hemifacial microsomia according to Pruzansky-Kaban types and growth stages
}

\author{
11-Hyung Yang ${ }^{\mathrm{a}}$ (1) \\ Jee Hyeok Chung ${ }^{b}$ (1) \\ Sunjin Yim ${ }^{\mathrm{c}}$ \\ 1l-Sik Cho ${ }^{\mathrm{d}}$ \\ Sukwha Kim ${ }^{\text {e }}$ \\ Jin-Young Choi ${ }^{\mathrm{f}}$ \\ Jong-Ho Lee ${ }^{f}$ \\ Myung-Jin Kim ${ }^{\mathrm{g}}$ \\ Seung-Hak Baek ${ }^{\mathrm{a}}$ (i)
}

${ }^{a}$ Department of Orthodontics, Dental Research Institute, School of Dentistry, Seoul National University, Seoul, Korea

bepartment of Plastic and

Reconstructive Surgery, Seoul National University Hospital, Seoul, Korea

'Department of Orthodontics, School of Dentistry, Seoul National University, Seoul, Korea

dPrivate Practice, Pohang, Korea

${ }^{e}$ Department of Plastic and Reconstructive Surgery, College of Medicine, Seoul National University, Seoul, Korea

'Department of Oral and Maxillofacial Surgery, School of Dentistry, Seoul National University, Seoul, Korea

${ }^{g}$ Private Practice, Seoul, Korea

\begin{abstract}
Objective: To investigate the treatment modalities (Tx-Mods) for patients with unilateral hemifacial microsomia (UHFM) according to Pruzansky-Kaban types and growth stages. Methods: The samples consisted of 82 Korean UHFM patients. Tx-Mods were defined as follows: Tx-Mod-1, growth observation due to mild facial asymmetry; Tx-Mod-2, unilateral functional appliance; TxMod-3, fixed orthodontic treatment; Tx-Mod-4, growth observation due to a definite need for surgical intervention; Tx-Mod-5, unilateral mandibular or bimaxillary distraction osteogenesis (D0); Tx-Mod-6, maxillary fixation using LeFort 1 osteotomy and mandibular D0/sagittal split ramus osteotomy; TxMod-7, orthognathic surgery; and Tx-Mod-8, costochondral grafting. The type and frequency of Tx-Mod, the number of patients who underwent surgical procedures, and the number of surgeries that each patient underwent, were investigated. Results: The degree of invasiveness and complexity of Tx-Mod increased, with an increase in treatment stage and Pruzansky-Kaban type (initial < final; [1, 1la] < [11b, 111], all $p<0.001$ ). The percentage of patients who underwent surgical procedures increased up to 4.2 times, with an increase in the Pruzansky-Kaban type (1, 24.1\%; 1la, 47.1\%; 1lb, 84.4\%; 111, 100\%; $p<0.001$ ). However, the mean number of surgical procedures that each patient underwent showed a tendency of increase according to the Pruzansky-Kaban types ( 1 , $\mathrm{n}=1.1 ; 1 \mathrm{la}, \mathrm{n}=1.5 ; \mathrm{llb}, \mathrm{n}=1.6 ; 111, \mathrm{n}=2.3 ; p>0.05)$. Conclusions: These findings might be used as basic guidelines for successful treatment planning and prognosis prediction in UHFM patients.
\end{abstract}

[Korean J Orthod 2020;50(5):336-345]

Key words: Treatment modality, Unilateral hemifacial microsomia

Received March 17, 2020; Revised June 5, 2020; Accepted June 10, 2020.

Corresponding author: Seung-Hak Baek.

Professor, Department of Orthodontics, Dental Research Institute, School of Dentistry, Seoul National University, 101, Daehak-ro, Jongno-gu, Seoul 03080, Korea.

Tel +82-2-2072-3952 e-mail drwhite@unitel.co.kr

ll-Hyung Yang and Jee Hyeok Chung contributed equally to this work (as co-first authors).

How to cite this article: Yang IH, Chung JH, Yim S, Cho IS, Kim S, Choi JY, Lee JH, Kim MJ, Baek SH. Treatment modalities for Korean patients with unilateral hemifacial microsomia according to Pruzansky-Kaban types and growth stages. Korean J Orthod 2020;50:336-345.

(C) 2020 The Korean Association of Orthodontists.

This is an Open Access article distributed under the terms of the Creative Commons Attribution Non-Commercial License (http://creativecommons.org/licenses/by-nc/4.0) which permits unrestricted non-commercial use, distribution, and reproduction in any medium, provided the original work is properly cited. 


\section{INTRODUCTION}

Hemifacial microsomia (HFM) is a congenital anomaly of the facial structures, that leads to hypoplasia of the mandible, maxilla, zygoma, calvarial bone, external and middle ear, masticatory muscles, facial and trigeminal nerves, and overlying soft tissue, with a broad spectrum of phenotypic manifestations. ${ }^{1-4}$ Most patients with HFM are treated using multi-disciplinary protocols to improve facial esthetics and rehabilitate the masticatory and respiratory functions. ${ }^{5-14}$

A wide range of treatment modalities (Tx-Mods) exists for HFM based on the age of the patient and the severity of the phenotypic manifestation. Although unified consensus regarding the indications, optimal method, and optimal timing for the surgical treatment of HFM is still insufficient, the severity of mandibular deformity in HFM patients (Figure 1) is one of the most important factors in determining the treatment method and predicting prognosis after treatment. ${ }^{3,5,13-18}$

There are two aspects to consider in surgical correction of HFM patients. First, the long-term outcome of surgical treatment is dependent on the severity of the mandibular deformity and facial asymmetry, rather than the type of surgical treatment (i.e., HFM patients with Pruzansky-Kaban type 1 and lla exhibited stable results compared to those with Pruzansky-Kaban type $\mathrm{llb}$ and 111). ${ }^{13,16}$ Second, surgical correction of moderate-tosevere facial asymmetry in HFM patients should be postponed till higher skeletal maturity is achieved, to reduce the number of surgical interventions and burden of care for HFM patients and their caregivers. ${ }^{13,16,19,20}$

Pluijmers et al., ${ }^{18}$ in their retrospective chart review study, reported meaningful clinical data on the type and frequency of surgical interventions from three different major hospitals. However, their study did not consider the time-frame for which HFM patients were treated or followed-up under the same treatment protocol and the age of patients which would provide information about their growth stage. ${ }^{18}$ Furthermore, there are no statistical studies on the type and frequency of orthodontic treatment for HFM patients. Therefore, the purpose of this retrospective study was to investigate the Tx-Mods for Korean patients with unilateral hemifacial microsomia (UHFM), including the type and frequency of orthodontic and surgical Tx-Mods, the number of patients who underwent surgical procedures, and the number of surgeries that each patient underwent, according to Pruzansky-Kaban types and growth stages, using strict criteria for the time period and the age of patients.

\section{MATERIALS AND METHODS}

\section{Subjects}

The samples consisted of 82 Korean patients with UHFM (43 male and 39 female; 37 with right-sided involvement and 45 with left-sided involvement; mean age at the initial stage, $7.60 \pm 4.68$ years), who were treated or followed-up at the Multi-disciplinary Clinic, Department of Pediatric Plastic and Reconstructive Sur-
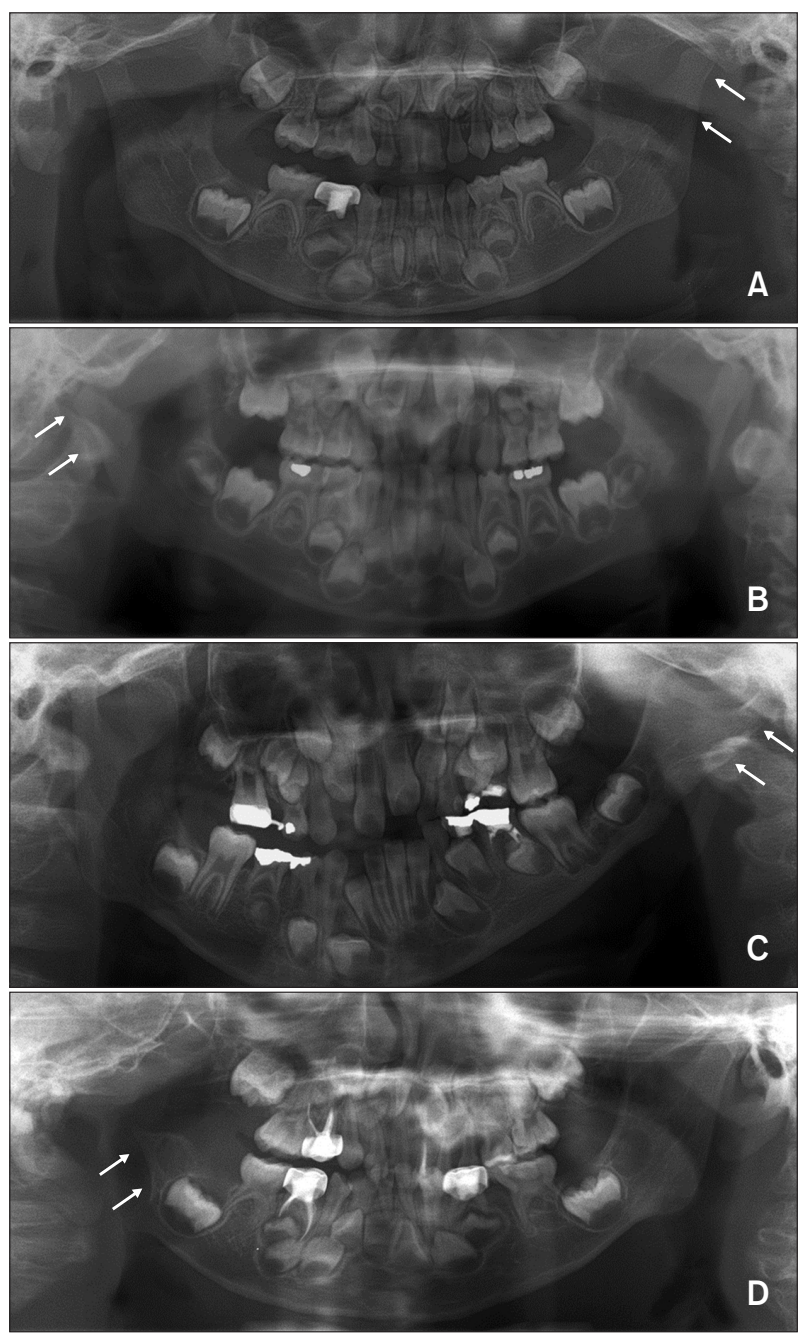

Figure 1. The Pruzansky-Kaban classification for hemifacial microsomia. A, Type I, the ramus/condyle complex has a normal shape but small size. $\mathbf{B}$, Type Ila, the ramus/ condyle complex is hypoplastic and abnormally shaped although the glenoid fossa is placed at the right position and the temporomandibular joint is functional. C, Type $\mathrm{Ilb}$, the glenoid fossa is placed at the inferiorly, medially, and anteriorly altered position with a severely hypoplastic ramus/condyle complex. D, Type III, complete absence of the ramus/condyle complex and the glenoid fossa. Arrow indicates the involvement side. 
gery of Seoul National University Children's Hospital and the Department of Oral and Maxillofacial Surgery and Department of Orthodontics of Seoul National University Dental Hospital (SNUDH) between 1998 and 2008.

The inclusion criteria were as follows: (1) patients who were born before 2005; (2) patients whose clinical chart, photographs, cephalograms, and orthopantomograms were available; and (3) patients whose skeletodental growth pattern could be evaluated using a longitudinal record. The initial stage referred to the time when the patient visited the clinic for the first time and the final stage indicated the time when the patient's latest treatment was accomplished.

The patients were divided into four groups, based on the Pruzansky-Kaban classification (type $1, n=29$; type lla, $n=17$; type $11 b, n=32$; and type $111, n=4$ ). This study was reviewed and approved by the Institutional Review Board of the SNUDH (ERI19043).

\section{Types of treatment modalities}

The orthodontic and surgical Tx-Mods for UHFM patients were classified into eight types according to the growth stage of patients and the degree of invasiveness and complexity of treatment modality: Tx-Mod-1, growth observation due to mild facial asymmetry; TxMod-2, unilateral functional appliance treatment; TxMod-3, fixed orthodontic treatment; Tx-Mod-4, growth observation due to a definite need for surgical intervention; Tx-Mod-5, unilateral mandibular or bimaxillary distraction osteogenesis (D0); Tx-Mod-6, fixation of the maxilla using LeFort 1 osteotomy for correcting the cant of the maxillary occlusal plane, and unilateral mandibular DO on the affected side and sagittal split ramus osteotomy (SSRO) on the unaffected side (Max-LeFort1-Man-DO/SSRO); ${ }^{10}$ Tx-Mod-7, orthognathic surgery including two-jaw surgery; and Tx-Mod-8, costochondral grafting with/without orthognathic surgery. If different Tx-Mods were consecutively used or combined at the final stage, the most invasive one was counted.

Tx-Mod-2 and Tx-Mod-3 were scored differently because of two reasons: First, Tx-Mod-2 is applied to patients before and during their adolescent period, while Tx-Mod-3 is applied to adolescent and adult patients. Second, Tx-Mod-2 is usually applied to PruznaskyKaban type 1 and lla patients only; while some adult patients received Tx-Mod-3 for pre- and post-operative orthodontic treatment in case of two-jaw surgery.

Tx-Mod-6 and Tx-Mod-7 were scored differently because of two reasons: First, Tx-Mod-6 is applied to adolescent patients, while Tx-Mod-7 is applied to adult patients. Second, since fixation of the maxilla after Le Fort 1 osteotomy in Tx-Mod-6 is performed just after the pubertal growth peak, it can correct the cant of the maxillary occlusal plane as well as reduce the further growth restriction of the maxilla in the affected side. In addition, vertical lengthening of the affected side by mandibular DO can help maintain the corrected maxillary occlusal plane cant and correct the chin point deviation. By using this approach, clinicians can reduce the possibility of major operation to correct the facial asymmetry and severe maxillary occlusal plane cant. However, without proper management of the problems mentioned above in the adolescent period, two-jaw surgery might be challenging in terms of the amount of surgical movement, and the degree of correction of facial asymmetry and maxillary occlusal plane cant.

\section{Variables}

The type of treatment modality, the number of patients who underwent surgical procedures, and the number of surgical procedures that each patient underwent were investigated.

\section{Statistical analysis}

Non-parametric statistical analysis including Fisher's exact test, Kruskal-Wallis test with Bonferroni correction, and mixed model analysis with Bonferroni method was adopted to overcome the unequal sample sizes between the groups using SPSS ver. 12.0 (SPSS Inc., Chicago, IL, USA). A $p$-value of less than 0.05 was considered statistically significant.

\section{RESULTS}

\section{Demographic data (Table 1)}

There were no significant differences with respect to sex, side involvement, and mean age at the initial stage among the Pruzansky-Kaban type groups (all $p>0.05$ ).

\section{Distribution of the type of treatment modality Pruzansky-Kaban type I group (Table 2)}

At the initial stage, growth observation (Tx-Mod-1 and Tx-Mod-4) was performed in $27.6 \%$ and $10.3 \%$ of the patients, respectively. At the final stage, growth observation (Tx-Mod-1) was performed in $41.3 \%$ of the patients.

The majority of type 1 patients was treated with a unilateral functional appliance at the initial stage (TxMod-2, 55.2\%), and with fixed orthodontic treatment and orthognathic surgery at the final stage (Tx-Mod-3, 34.5\%; Tx-Mod-7, 20.7\%).

\section{Pruzansky-Kaban type lla group (Table 3)}

At the initial stage, growth observation (Tx-Mod-1 and Tx-Mod-4) was performed in $47.1 \%$ and $17.6 \%$ of the patients, respectively. At the final stage, growth observation (Tx-Mod-1) was performed in $47.1 \%$ of the patients. 
Table 1. Demographic data of unilateral hemifacial microsomia patients

\begin{tabular}{lcccccc}
\hline & \multirow{2}{*}{ Variable } & \multicolumn{5}{c}{ Pruzansky-Kaban type } \\
\cline { 3 - 6 } & $(\mathbf{n = 8 2})$ & $\begin{array}{c}\text { Type I } \\
(\mathbf{n = 2 9 )}\end{array}$ & $\begin{array}{c}\text { Type IIa } \\
(\mathbf{n}=\mathbf{1 7})\end{array}$ & $\begin{array}{c}\text { Type IIb } \\
(\mathbf{n}=\mathbf{3 2})\end{array}$ & $\begin{array}{c}\text { Type III } \\
(\mathbf{n}=\mathbf{4})\end{array}$ & p-value \\
\hline Distribution of sex (male:female) & $43: 39$ & $14: 15$ & $9: 8$ & $18: 14$ & $2: 2$ & $0.939^{*}$ \\
Side involvement (right:left) & $37: 45$ & $14: 15$ & $9: 8$ & $12: 20$ & $2: 2$ & $0.719^{*}$ \\
Mean age at the first consultation (yr) & $7.60 \pm 4.68$ & $7.11 \pm 4.22$ & $5.45 \pm 2.72$ & $8.63 \pm 5.78$ & $7.14 \pm 1.81$ & $0.138^{\dagger}$ \\
\hline
\end{tabular}

Values are presented as number only or mean \pm standard deviation.

*Fisher's exact test was performed.

${ }^{\dagger}$ Kruskal-Wallis test with Bonferroni correction was performed.

Table 2. Distribution of the type of treatment modality in the Pruzansky-Kaban type I group

\begin{tabular}{|c|c|c|c|}
\hline \multirow{3}{*}{$\begin{array}{l}\text { Previous } \\
\text { surgical } \\
\text { treatment } \\
\text { history }\end{array}$} & \multicolumn{3}{|c|}{ Pruzansky-Kaban type I (n = 29) } \\
\hline & \multicolumn{3}{|c|}{ Tx-Mod } \\
\hline & \multicolumn{2}{|c|}{ Tx-Mod performed at the initial stage } & Tx-Mod performed at the final stage \\
\hline \multirow[t]{9}{*}{$\mathrm{n}=0(0 \%)$} & $\begin{array}{l}\text { Growth } \\
\text { observation }\end{array}$ & $\begin{array}{l}\text { Tx-Mod-1 } \\
\text { Growth observation }(n=8,27.6 \%)\end{array}$ & $\begin{array}{l}\text { Tx-Mod-1 } \\
\text { Growth observation }(n=7,24.1 \%)\end{array}$ \\
\hline & & & $\begin{array}{l}\text { Tx-Mod-3 } \\
\text { Fixed-Ortho-Tx }(\mathrm{n}=1,3.4 \%)\end{array}$ \\
\hline & & $\begin{array}{l}\text { Tx-Mod-4 } \\
\text { Growth observation }(n=3,10.3 \%)\end{array}$ & $\begin{array}{l}\text { Tx-Mod-7 } \\
\text { Fixed-Ortho-Tx + two-jaw surgery }(n=3,10.3 \%)\end{array}$ \\
\hline & $\begin{array}{l}\text { Orthodontic } \\
\text { treatment }\end{array}$ & $\begin{array}{l}\text { Tx-Mod-2 } \\
\text { Growth modification using unilateral } \\
\text { functional appliance (Unilat-Fx-App) } \\
(\mathrm{n}=16,55.2 \%)\end{array}$ & $\begin{array}{l}\text { Tx-Mod-1 } \\
\text { Growth observation }(n=5,17.2 \%)\end{array}$ \\
\hline & & & $\begin{array}{l}\text { Tx-Mod-3 } \\
\text { Fixed-Ortho-Tx }(n=8,27.6 \%)\end{array}$ \\
\hline & & & $\begin{array}{l}\text { Tx-Mod-5 } \\
\text { Fixed-Ortho-Tx + Unilat-Man-DO }(n=1,3.4 \%)\end{array}$ \\
\hline & & & $\begin{array}{l}\text { Tx-Mod-7 } \\
\text { Fixed-Ortho-Tx + growth observation } \\
+ \text { two-jaw surgery }(\mathrm{n}=2,6.9 \%)\end{array}$ \\
\hline & & $\begin{array}{l}\text { Tx-Mod-3 } \\
\text { Fixed orthodontic treatment using } \\
\text { brackets and wires (Fixed-Ortho-Tx) } \\
(\mathrm{n}=1,3.4 \%)\end{array}$ & $\begin{array}{l}\text { Tx-Mod-3 } \\
\text { Fixed-Ortho-Tx }(\mathrm{n}=1,3.4 \%)\end{array}$ \\
\hline & $\begin{array}{l}\text { Surgical } \\
\text { treatment }\end{array}$ & $\begin{array}{l}\text { Tx-Mod-5 } \\
\text { Unilateral mandibular distraction } \\
\text { osteogenesis (Unilat-Man-DO) } \\
(\mathrm{n}=1,3.4 \%)\end{array}$ & $\begin{array}{l}\text { Tx-Mod-7 } \\
\text { Fixed-Ortho-Tx + two-jaw surgery } \\
(\mathrm{n}=1,3.4 \%)\end{array}$ \\
\hline
\end{tabular}

Growth observation included Tx-Mod-1 and Tx-Mod-4. Orthodontic treatment consisted of Tx-Mod-2 and Tx-Mod-3. Surgical treatment comprised of Tx-Mod-5, Tx-Mod-6, Tx-Mod-7, and Tx-Mod-8. If different treatment modalities were consecutively used or combined at the final stage, the most invasive one was counted.

Tx-Mod, Treatment modality; Tx-Mod-1, growth observation due to mild facial asymmetry; Tx-Mod-2, growth modification using unilateral functional appliance and other appliances; Tx-Mod-3, fixed orthodontic treatment using brackets and wires; Tx-Mod-4, growth observation due to significant facial asymmetry or a definite need for surgical intervention when higher skeletal maturity is achieved or even after the completion of growth; Tx-Mod-5, unilateral mandibular or bimaxillary distraction osteogenesis (DO); Tx-Mod-6, fixation of the maxilla using LeFort I osteotomy for correcting the cant of the maxillary occlusal plane, and unilateral mandibular DO on the affected side and sagittal split ramus osteotomy (SSRO) on the unaffected side for correction of chin point deviation and facial asymmetry (Max-LeFort-I-Man-DO/SSRO); ${ }^{10}$ Tx-Mod-7, orthognathic surgery including two-jaw surgery; and Tx-Mod-8, costochondral grafting with/without orthognathic surgery. 
Table 3. Distribution of the type of treatment modality in the Pruzansky-Kaban type Ila group

\begin{tabular}{|c|c|c|c|}
\hline \multirow{3}{*}{$\begin{array}{l}\text { Previous surgical } \\
\text { treatment history }\end{array}$} & \multicolumn{3}{|c|}{ Pruzansky-Kaban type IIa $(\mathrm{n}=17)$} \\
\hline & \multicolumn{3}{|c|}{ Tx-Mod } \\
\hline & \multicolumn{2}{|c|}{ Tx-Mod performed at the initial stage } & Tx-Mod performed at the final stage \\
\hline \multirow[t]{6}{*}{$\mathrm{n}=0(0 \%)$} & $\begin{array}{l}\text { Growth } \\
\text { observation }\end{array}$ & $\begin{array}{l}\text { Tx-Mod-1 } \\
\text { Growth observation }(n=8,47.1 \%)\end{array}$ & $\begin{array}{l}\text { Tx-Mod-1 } \\
\text { Growth observation }(n=8,47.1 \%)\end{array}$ \\
\hline & & $\begin{array}{l}\text { Tx-Mod-4 } \\
\text { Growth observation }(n=3,17.6 \%)\end{array}$ & $\begin{array}{l}\text { Tx-Mod-7 } \\
\text { Fixed-Ortho-Tx + growth observation } \\
+ \text { two-jaw surgery }(n=3,17.6 \%)\end{array}$ \\
\hline & $\begin{array}{l}\text { Orthodontic } \\
\text { treatment }\end{array}$ & $\begin{array}{l}\text { Tx-Mod-2 } \\
\text { Growth modification using } \\
\text { Unilat-Fx-App }(\mathrm{n}=2,11.8 \%)\end{array}$ & $\begin{array}{l}\text { Tx-Mod-2 } \\
\text { Growth modification using } \\
\text { Unilat-Fx-App }(\mathrm{n}=1,5.9 \%)\end{array}$ \\
\hline & & & $\begin{array}{l}\text { Tx-Mod-7 } \\
\text { Fixed-Ortho-Tx + Unilat-Man-DO + growth } \\
\text { observation + two-jaw surgery }(\mathrm{n}=1,5.9 \%)\end{array}$ \\
\hline & $\begin{array}{l}\text { Surgical } \\
\text { treatment }\end{array}$ & $\begin{array}{l}\text { Tx-Mod-5 } \\
\text { Unilat-Man-DO }(\mathrm{n}=4,23.5 \%)\end{array}$ & $\begin{array}{l}\text { Tx-Mod-3 } \\
\text { Growth observation + Fixed-Ortho-Tx } \\
(\mathrm{n}=1,5.9 \%)\end{array}$ \\
\hline & & & $\begin{array}{l}\text { Tx-Mod-7 } \\
\text { Growth observation + Fixed-Ortho-Tx + } \\
\text { two-jaw surgery }(n=3,17.6 \%)\end{array}$ \\
\hline
\end{tabular}

See Table 2 definitions of Tx-Mods.

At the initial stage, $35.3 \%$ of type lla patients were treated with unilateral mandibular DO and unilateral functional appliance (Tx-Mod-5, 23.5\%; Tx-Mod-2, $11.8 \%$ ). However, at the final stage, $41.2 \%$ of the patients were treated with orthognathic surgery (TxMod-7).

\section{Pruzansky-Kaban type Ilb group (Table 4)}

Among type $11 \mathrm{~b}$ patients, $21.9 \%$ had a history of surgical treatment ( 5 patients with unilateral mandibular DO, 1 patient with unilateral maxillary DO, and 1 patient with Max-LeFort-l-Man-DO/SSRO).

At the initial stage, growth observation (Tx-Mod-1 and Tx-Mod-4) was performed in 12.5\% and 28.1\% of the patients, respectively. At the final stage, growth observation (Tx-Mod-1) was performed in 12.5\% of the patients.

At the initial stage, $50.1 \%$ of type $11 \mathrm{~b}$ patients were treated with orthodontic treatment (fixed orthodontic treatment, Tx-Mod-3, 31.3\% and unilateral functional appliance treatment, Tx-Mod-2, 18.8\%). However, surgical treatment including unilateral mandibular or bimaxillary DO (Tx-Mod-5, 6.2\%) and Max-LeFort-1Man-DO/bilateral SSRO (BSSRO) (Tx-Mod-6, 3.1\%) was performed in only $9.3 \%$ of the patients.

At the final stage, surgical treatment was the most frequently used treatment modality (84.4\%) including orthognathic surgery (Tx-Mod-7, 59.4\%), Max-LeFort-lMan-DO/BSSRO (Tx-Mod-6, 12.5\%), unilateral mandib- ular D0 (Tx-Mod-5, 9.4\%), and costochondral grafting with/without orthognathic surgery (Tx-Mod-8, 3.1\%). However, orthodontic treatment (Tx-Mod-3) was used in only $3.1 \%$ of the patients.

\section{Pruzansky-Kaban type III group (Table 5)}

Half of type 111 patients had a history of surgical treatment (1 patient with unilateral mandibular DO and 1 patient with costochondral grafting).

At the initial stage, only growth observation (TxMod-4, 100\%) was used. At the final stage, only costochondral grafting with/without orthognathic surgery was used (Tx-Mod-8, 100\%).

Comparison of the treatment modalities according to the Pruzansky-Kaban type and treatment stage (Table 6)

The more invasive and complex Tx-Mods were used for Pruzansky-Kaban types $11 \mathrm{~b}$ and 111 compared to those for Pruzansky-Kaban types 1 and 1la ([1, 1la] < [11b, 111], $p<0.001)$. When the initial and final stages were compared to determine if the patients had undergone different Tx-Mods, the degree of invasiveness and complexity in the treatment modality at the final stage was higher than that at the initial stage (initial $<$ final, $p<0.001$ ).

Comparison of the number of patients who underwent surgical procedures (Table 7)

In total, 56.1\% of the patients ( $n=46$ of 82 ) had surgical treatment (Tx-Mod-5, 6, 7, and 8) during the 
Table 4. Distribution of the type of treatment modality in the Pruzansky-Kaban type Ilb group

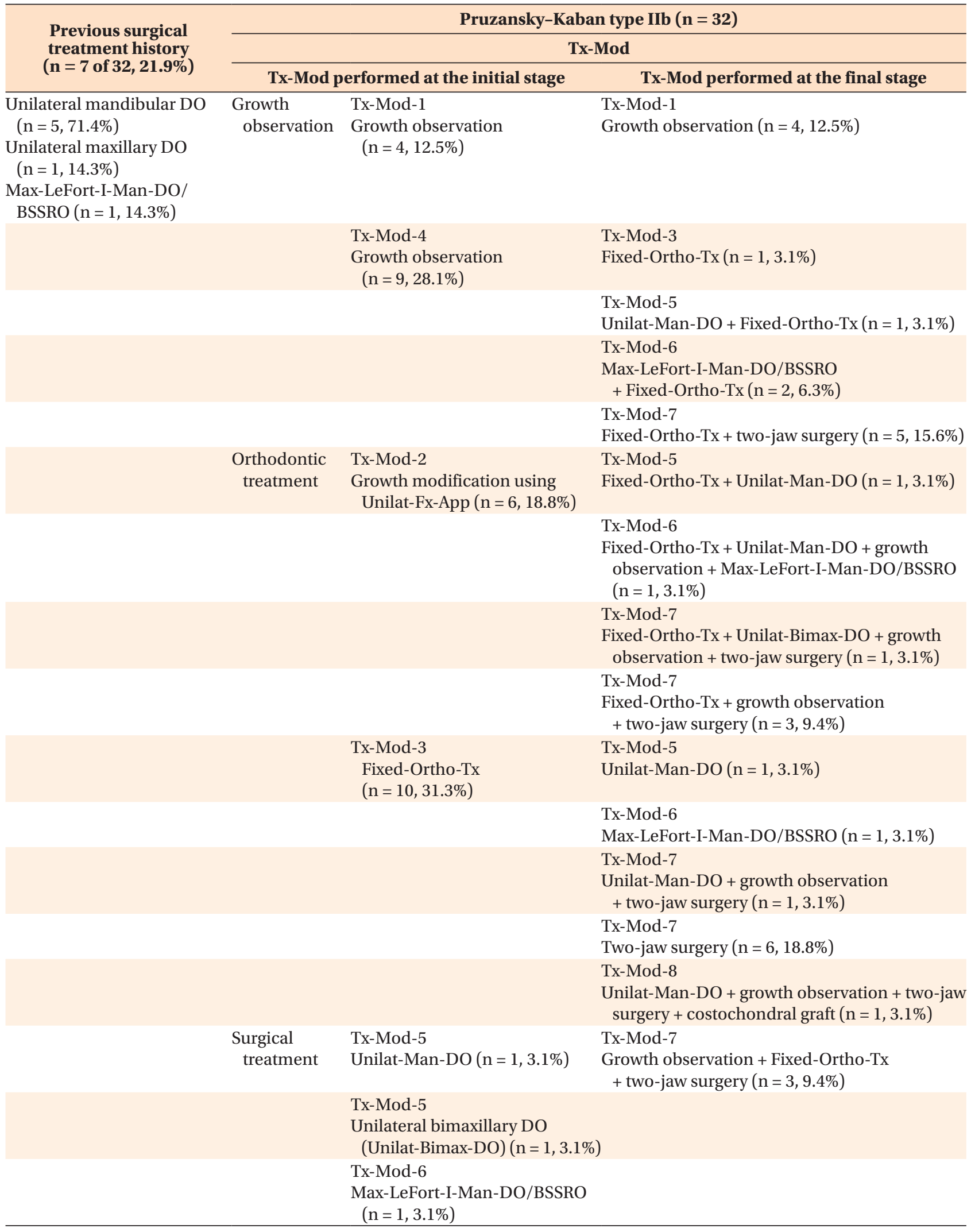

BSSRO, Bilateral sagittal split ramus osteotomy.

See Table 2 definitions of Tx-Mods. 
Table 5. Distribution of the type of treatment modality in the Pruzansky-Kaban type III group

\begin{tabular}{|c|c|c|}
\hline \multirow{3}{*}{$\begin{array}{l}\text { Previous surgical } \\
\text { treatment history } \\
(n=2 \text { of } 4,50 \%)\end{array}$} & \multicolumn{2}{|c|}{ Pruzansky-Kaban type III $(n=4)$} \\
\hline & \multicolumn{2}{|r|}{ Tx-Mod } \\
\hline & Tx-Mod performed at the initial stage & Tx-Mod performed at the final stage \\
\hline \multirow{4}{*}{$\begin{array}{l}\text { Unilateral mandibula } \\
(\mathrm{n}=1,50 \%) \\
\text { Costochondral graft } \\
(\mathrm{n}=1,50 \%)\end{array}$} & $\begin{array}{l}\text { Tx-Mod-4 } \\
\text { Growth observation }(n=4,100 \%)\end{array}$ & $\begin{array}{l}\text { Tx-Mod-8 } \\
\text { Two-jaw surgery + costochondral grafting }(n=1,25 \%)\end{array}$ \\
\hline & & $\begin{array}{l}\text { Tx-Mod-8 } \\
\text { Fixed-Ortho-Tx + costochondral grafting } \\
+ \text { growth observation + two-jaw surgery }(n=1,25 \%)\end{array}$ \\
\hline & & $\begin{array}{l}\text { Tx-Mod-8 } \\
\text { Fixed-Ortho-Tx + costochondral grafting } \\
\quad+\text { growth observation }(n=1,25 \%)\end{array}$ \\
\hline & & $\begin{array}{l}\text { Tx-Mod-8 } \\
\text { Fixed-Ortho-Tx + two-jaw surgery } \\
\quad+\text { costochondral grafting }(\mathrm{n}=1,25 \%)\end{array}$ \\
\hline
\end{tabular}

See Table 2 definitions of Tx-Mods.

Table 6. Comparison of the degree of invasiveness of treatment modalities according to the Pruzansky-Kaban type and treatment stage

\begin{tabular}{ccccc}
\hline \multirow{2}{*}{$\begin{array}{c}\text { Pruzansky-Kaban } \\
\text { type }\end{array}$} & \multicolumn{2}{c}{ Treatment modality } & Pruzansky-Kaban type & Treatment stage \\
\cline { 2 - 3 } & Initial stage & Final stage & & \\
\hline I (n = 29) & $2.07 \pm 1.03$ & $3.07 \pm 2.30$ & & $<0.001^{* * *}$ \\
IIa (n= 17) & $2.59 \pm 1.77$ & $3.65 \pm 2.94$ & $<0.001^{* * *}$ & Initial $<$ final \\
IIb (n=32) & $2.97 \pm 1.10$ & $5.84 \pm 2.08$ & (I, IIa) $<$ (IIb, III) & \\
III ( $=4)$ & $4.00 \pm 0.00$ & $8.00 \pm 0.00$ & & \\
\hline
\end{tabular}

Values are presented as mean \pm standard deviation.

Mixed model analysis and Bonferroni test for post hoc multiple comparison were performed.

Interaction $(p=0.008)$ occurred due to a small amount of difference in the treatment modality at the initial stage between the Pruzansky-Kaban type IIa and IIb groups (2.59 vs. 2.97).

${ }^{* * *} p<0.001$.

Table 7. Comparison of the number of patients who underwent surgical procedures among the Pruzansky-Kaban type groups

\begin{tabular}{ccccc}
\hline \multirow{2}{*}{ Pruzansky-Kaban type } & \multicolumn{4}{c}{ Patients who underwent surgical procedures } \\
\cline { 2 - 5 } & Number & Percentage & Exp(B) & p-value \\
\hline I & $7 / 29$ & 24.1 & \\
IIa & $8 / 17$ & 47.1 & 4.242 & $<0.001^{* * *}$ \\
IIb & $27 / 32$ & 84.4 & \\
III & $4 / 4$ & 100.0 & \\
\hline
\end{tabular}

Logistic regression analysis was performed.

${ }^{* * *} p<0.001$.

treatment period. The number of patients who had surgical procedures increased up to 4.2 times, with an increase in the severity of HFM (type l, $n=7$ of 29 [24.1\%]; type lla, $n=8$ of 17 [47.1\%]; type $11 \mathrm{~b}, \mathrm{n}=27$ of 32
[84.4\%]; type 111, $\mathrm{n}=4$ of 4 [100\%]; $p<0.001 ; \operatorname{Exp}(\mathrm{B})$ $=4.242$ ). 
Table 8. Comparison of the number of surgeries that each patient underwent and the number of patients who underwent multiple surgical procedures among the Pruzansky-Kaban type groups

\begin{tabular}{|c|c|c|c|c|c|c|}
\hline \multirow{2}{*}{$\begin{array}{c}\text { Pruzansky-Kaban } \\
\text { type }\end{array}$} & \multicolumn{3}{|c|}{$\begin{array}{l}\text { Number of surgical procedures in patients } \\
\text { who underwent surgery }\end{array}$} & \multicolumn{3}{|c|}{$\begin{array}{l}\text { Number of patients who underwent multiple } \\
\text { surgical procedures }\end{array}$} \\
\hline & Mean & SD & $p$-value & Number & Percentage & $p$-value \\
\hline $\mathrm{I}(\mathrm{n}=7)$ & 1.14 & 0.38 & \multirow{4}{*}{$0.154^{*}$} & $1 / 7$ & 14.3 & \multirow{4}{*}{$0.267^{\dagger}$} \\
\hline IIa $(\mathrm{n}=8)$ & 1.50 & 0.54 & & $4 / 8$ & 50.0 & \\
\hline $\operatorname{IIb}(\mathrm{n}=27)$ & 1.63 & 0.88 & & $12 / 27$ & 44.4 & \\
\hline $\mathrm{III}(\mathrm{n}=4)$ & 2.25 & 0.96 & & $3 / 4$ & 75.0 & \\
\hline
\end{tabular}

SD, Standard deviation.

*Kruskal-Wallis test was performed.

†Fisher's exact test was performed.

Comparison of the mean number of surgeries that each patient underwent and the number of patients who underwent multiple surgical procedures (Table 8)

Despite a tendency of increase in the mean number of surgical procedures from type 1 to type 111 , there was no statistically significant difference among the PruzanskyKaban types (type l, $\mathrm{n}=1.1$; type lla, $\mathrm{n}=1.5$; type $1 \mathrm{lb}$, $\mathrm{n}=1.6$; and type 111, $\mathrm{n}=2.3 ; p>0.05$ ).

No statistically significant difference was observed in the number of patients who had multiple surgical procedures among the Pruzansky-Kaban types, although type 1 patients showed a lower percentage compared to the other types (type l, $n=1$ [14.3\%]; type lla, $n=4$ [50.0\%]; type $11 \mathrm{~b}, \mathrm{n}=12$ [44.4\%]; and type $111, \mathrm{n}=3$ [75.0\%]; $p>0.05)$.

\section{DISCUSSION}

\section{Demographic data}

There were no significant differences in the distribution of sex and side involvement among the PruzanskyKaban type groups (Table 1). These findings were similar to the results of previous studies, despite the difference in geographical and ethnic factors. ${ }^{19,21,22}$

\section{Distribution of the type of treatment modality Pruzansky-Kaban type I group (Table 2)}

The finding that growth observation (Tx-Mod-1) was performed in $27.6 \%$ of the patients at the initial stage and $41.3 \%$ of the patients at the final stage indicates that some of the parents did not demand any type of treatment, when a type 1 patient presented mild facial asymmetry.

At the initial stage, the majority of type 1 patients were treated with a unilateral functional appliance (TxMod-2, 55.2\%), which implies that parents wanted a conservative treatment modality to correct mild facial asymmetry. Then, at the final stage, $34.5 \%$ of the patients were treated with fixed orthodontic treatment (Tx-
Mod-3), while $20.7 \%$ desired correction of the residual facial asymmetry with orthognathic surgery (Tx-Mod-7).

\section{Pruzansky-Kaban type lla group (Table 3)}

Growth observation (Tx-Mod-1) was performed in $47.1 \%$ of the patients at both initial and final stages, respectively. These findings indicate that clinicians wanted to observe the growth pattern of type lla patients with mild-to-moderate facial asymmetry before deciding the treatment modality.

At the initial stage, 35.3\% of type lla patients were treated with unilateral mandibular DO and unilateral functional appliance (Tx-Mod-5, 23.5\%; Tx-Mod-2, $11.8 \%$ ), which implies that clinicians wanted to correct facial asymmetry with unilateral mandibular DO or unilateral functional appliance. However, at the final stage, $41.2 \%$ of the patients had a more invasive treatment modality, such as orthognathic surgery (Tx-Mod-7).

\section{Pruzansky-Kaban type Ilb group (Table 4)}

At the initial stage, the frequency of Tx-Mod-4 growth observation was two times higher than that of Tx-Mod-1 growth observation (28.1\% vs. $12.5 \%)$. This finding indicates that clinicians wanted to wait till the skeletal age was matured or facial growth was completed before deciding a specific surgical treatment modality for some of the type $11 \mathrm{~b}$ patients with moderate-tosevere facial asymmetry (28.1\%).

At the initial stage, half of the type llb patients (50.1\%) received orthodontic treatment (Tx-Mod-3, 31.3\%; TxMod-2, 18.8\%), which indicates that clinicians wanted to treat the patient's malocclusion with orthodontic treatment approach and then observe the facial growth due to the unfavorable prognosis of surgical treatment.

At the final stage, surgical treatment was the most common treatment modality for type llb patients (84.4\%) (Tx-Mod-7, 59.4\%; Tx-Mod-6, 12.5\%; Tx-Mod-5, 9.4\%; and Tx-Mod-8, 3.1\%), which indicates that clinicians wanted to treat the patient's skeletal problem and fa- 
cial asymmetry with surgery after the facial growth was completed.

\section{Pruzansky-Kaban type III group (Table 5)}

At the initial stage, growth observation (Tx-Mod-4) was performed in all of the patients, which indicates that since type 111 patients had severe facial asymmetry because the ramus/condyle complex was absent on the affected side, clinicians did not want to perform any type of treatment before completion of the facial growth.

At the final stage, all type 111 patients were treated with the most invasive treatment modality (costochondral grafting with/without orthognathic surgery, Tx-Mod-8) to reconstruct the ramus/condyle complex of the mandible on the affected side and to correct the maxillary cant and facial asymmetry.

\section{Comparison of the degree of invasiveness of treatment modalities according to the Pruzansky-Kaban type and treatment stage (Table 6)}

In the present study, the patients with PruzanskyKaban types $11 \mathrm{lb}$ and 111 were treated with more invasive and complex Tx-Mods, compared to those with Pruzansky-Kaban types 1 and 1la ([1, 1la] < [11b, 111], $p<0.001$ ). This finding indicates that clinicians wanted to treat the patient's skeletodental problem and facial asymmetry with orthodontic treatment approach in mild-to-moderate cases and with surgery in moderate-to-severe cases.

The finding that the degree of invasiveness and complexity in the treatment modality at the final stage was higher than that of the initial stage (initial < final, $p<0.001)$ implies that clinicians wanted to treat the patient's malocclusion using orthodontic treatment approach before and during pubertal growth and correct the patient's skeletal problem and facial asymmetry with surgery after completion of facial growth to avoid unnecessary multiple surgical procedures.

\section{Comparison of the number of patients who underwent surgical procedures (Table 7)}

In the present study, $56.1 \%$ of the patients ( $\mathrm{n}=$ 46/82) underwent surgical treatment (Tx-Mod-5, 6, 7, and 8) during the treatment period. This finding was similar to the results of Pluijmers et al., ${ }^{18}$ which reported that $42.7 \%$ and $16.5 \%$ of the patients underwent surgery for the mandible and maxilla, respectively.

When the Pruzansky-Kaban type worsened from type 1 to type 111 , the number of patients who underwent surgical procedures was increased up to 4.2 times $(p<$ 0.001). This finding was similar to the results of systematic analysis conducted by van de Lande et al. ${ }^{17}$

\section{Comparison of the mean number of surgical procedures} that each patient underwent (Table 8)

The finding that the mean number of surgical procedures that each patient underwent increased from the type 1 group to the type 111 group, despite the lack of statistical significance (type $1, n=1.1$; type lla, $n=1.5$; type $11 \mathrm{~b}, \mathrm{n}=1.6$; and type $111, \mathrm{n}=2.3$ ) was similar to that of Pluijmers et al. ${ }^{18}$ (type $1, \mathrm{n}=1.0$; type lla, $\mathrm{n}=1.4$; type $11 b, n=1.8$; and type $111, n=2.3$ ).

\section{Comparison of the number of patients who underwent multiple surgical procedures (Table 8)}

The number of patients who underwent multiple surgical procedures was higher in the type $11 \mathrm{a}, \mathrm{llb}$, and 111 groups compared to the type 1 group, despite the lack of statistical significance (type $1, n=1$ [14.3\%]; type lla, $n$ $=4[50.0 \%]$; type $11 \mathrm{~b}, \mathrm{n}=12[44.4 \%]$; and type $111, \mathrm{n}=$ $3[75.0 \%])$. This result was similar to that of Pluijmers et al., ${ }^{18}$ which observed that $49.1 \%$ and $61 \%$ of PruzanskyKaban type $\mathrm{llb}$ and $\mathrm{lll}$ patients needed multiple operations, respectively.

The main objective of this study was to investigate the Tx-Mods for patients with UHFM according to its invasiveness and complexity by using longitudinal data. However, there are several suggestions for future studies in order to establish sophisticated study designs and obtain comparable outcomes. First, it is necessary to develop a uniform registration and outcome measurement tool to compare the results between different Tx-Mods. ${ }^{18}$ Second, a nationwide multi-center prospective study and systematic statistical analyses should be performed. Third, it is necessary to investigate the type and frequency of orthodontic and surgical Tx-Mods for bilateral HFM patients, which requires a greater number of multiple surgical procedures compared to UHFM patients.

\section{CONCLUSION}

- The two main findings of this study were as follows: (1) With worsening of the Pruzansky-Kaban types, the degree of invasiveness and complexity of treatment modality and the percentage of patients who underwent surgical procedures significantly increased, and (2) The degree of invasiveness and complexity in the treatment modality at the final stage was significantly higher than that at the initial stage.

- These findings indicate that when the patients have a severe Pruzansky-Kaban type and get older in terms of treatment timing, the degree of invasiveness and complexity in the treatment modality increases.

- These results might be used as basic guidelines for successful treatment planning and prognosis prediction of HFM patients and provide primary information for 
health care utilization in orthodontic and surgical treatment of patients with HFM in the future.

\section{CONFLICTS OF INTEREST}

No potential conflict of interest relevant to this article was reported.

\section{REFERENCES}

1. Grabb WC. The first and second branchial arch syndrome. Plast Reconstr Surg 1965;36:485-508.

2. Poswillo D. Hemorrhage in development of the face. Birth Defects Orig Artic Ser 1975;11:61-81.

3. Figueroa AA, Pruzansky S. The external ear, mandible and other components of hemifacial microsomia. J Maxillofac Surg 1982;10:200-11.

4. Hartsfield JK. Review of the etiologic heterogeneity of the oculo-auriculo-vertebral spectrum (hemifacial microsomia). Orthod Craniofac Res 2007;10:121-8.

5. Kaban LB, Moses MH, Mulliken JB. Correction of hemifacial microsomia in the growing child: a follow-up study. Cleft Palate J 1986;23 Suppl 1:50-2.

6. Cousley RR, Calvert ML. Current concepts in the understanding and management of hemifacial microsomia. Br J Plast Surg 1997;50:536-51.

7. Choi JY, Hwang KG, Baek SH, Lee JH, Kim TW, Kim $\mathrm{MJ}$, et al. Original sagittal split osteotomy revisited for mandibular distraction. J Craniomaxillofac Surg 2001;29:165-73.

8. McCarthy JG, Katzen JT, Hopper R, Grayson BH. The first decade of mandibular distraction: lessons we have learned. Plast Reconstr Surg 2002;110:170413.

9. Ohtani J, Hoffman WY, Vargervik K, Oberoi S. Team management and treatment outcomes for patients with hemifacial microsomia. Am J Orthod Dentofacial Orthop 2012;141(4 Suppl):S74-81.

10. Kim S, Seo YJ, Choi TH, Baek SH. New approach for the surgico-orthodontic treatment of hemifacial microsomia. J Craniofac Surg 2012;23:957-63.

11. Heike CL, Hing AV, Aspinall CA, Bartlett SP, Birgfeld CB, Drake AF, et al. Clinical care in craniofacial microsomia: a review of current management recommendations and opportunities to advance research. Am J Med Genet C Semin Med Genet 2013;
163C:271-82.

12. Suh J, Choi TH, Baek SH, Kim JC, Kim S. Mandibular distraction in unilateral craniofacial microsomia: longitudinal results until the completion of growth. Plast Reconstr Surg 2013;132:1244-52.

13. Pluijmers Bl, Caron CJ, Dunaway DJ, Wolvius EB, Koudstaal MJ. Mandibular reconstruction in the growing patient with unilateral craniofacial microsomia: a systematic review. Int J Oral Maxillofac Surg 2014;43:286-95.

14. Yang $\mathrm{HH}$, Chung JH, Yim S, Cho IS, Lim SW, Kim K, et al. Distribution and phenotypes of hemifacial microsomia and its association with other anomalies. Korean J Orthod 2020;50:33-41.

15. Mulliken JB, Kaban LB. Analysis and treatment of hemifacial microsomia in childhood. Clin Plast Surg 1987;14:91-100.

16. Baek SH, Kim S. The determinants of successful distraction osteogenesis of the mandible in hemifacial microsomia from longitudinal results. J Craniofac Surg 2005;16:549-58.

17. van de Lande LS, Pluijmers Bl, Caron CJJM, Wolvius EB, Dunaway DJ, Koudstaal MJ, et al. Surgical correction of the midface in craniofacial microsomia. Part 1: a systematic review. J Craniomaxillofac Surg 2018;46:1427-35.

18. Pluijmers Bl, Caron CJJM, van de Lande LS, Schaal S, Mathijssen IM, Wolvius EB, et al. Surgical correction of craniofacial microsomia: evaluation of interventions in 565 patients at three major craniofacial units. Plast Reconstr Surg 2019;143:1467-76.

19. Huisinga-Fischer CE, Vaandrager JM, Prahl-Andersen $\mathrm{B}$. Longitudinal results of mandibular distraction osteogenesis in hemifacial microsomia. J Craniofac Surg 2003;14:924-33.

20. Nagy K, Kuijpers-Jagtman AM, Mommaerts MY. No evidence for long-term effectiveness of early osteodistraction in hemifacial microsomia. Plast Reconstr Surg 2009;124:2061-71.

21. Vento AR, LaBrie RA, Mulliken JB. The O.M.E.N.S. classification of hemifacial microsomia. Cleft Palate Craniofac J 1991;28:68-76; discussion 77.

22. Xu S, Zhang Z, Tang X, Yin L, Liu W, Shi L. The influence of gender and laterality on the incidence of hemifacial microsomia. J Craniofac Surg 2015;26:384-7. 